\title{
Effect of prostaglandin on reproduction in relation to pituitary gonadal axis in the fish, Cyprinus carpio (L.)
}

\author{
Veena Dongre ${ }^{1 *}$, R.C. Dabhade ${ }^{1}$ and A . M . K hurad ${ }^{2}$ \\ ${ }^{1}$ Department of Zoology, S.K. Porwal College, Kamptee - 441002 (Maharashtra), INDIA \\ ${ }^{2}$ Post-graduate Department of Zoology, RTM Nagpur University, Nagpur - 440033 (Maharashtra), INDIA \\ *Corresponding author. E-mail: veena_dongre@yahoo.com \\ Received:J uly 20,2011; Revised received: March 12, 2012; Accepted: August 14, 2012
}

\begin{abstract}
Prostaglandins are a class of fatty acids which are "traditionally" associated with a variety of autocrine and paracrine functions in the vertebrate body. In many fishes, however, F prostaglandins also function as a hormone that stimulates sexual behavior. In the present study, F prostaglandin was used to assess the efficacy on reproductive behavior and spawning in relation to pituitary gonadal axis in the fish, Cyprinus carpio by administering different doses. Early maturity was observed in fish leading to courtship and spawning. The histological study of olfactory lobe, pituitary gland and gonads showed that the prostaglandin is also functioning as potent olfactory stimulants with sex pheromonal activity of the fish. $F$ prostaglandin was metabolized and released into the water where it functions as a sex pheromone, stimulating male and female sexual behavior resulting into spawning. It was concluded that $\mathrm{F}$ prostaglandin acts as an inducer for successful breeding in the fish, $\mathrm{C}$. carpio.
\end{abstract}

Keywords: Courtship, F Prostaglandin, Inducer, Sex pheromone, Spawning behaviour

\section{INTRODUCTION}

Prostaglandins are like hormones in that they act as chemical messenger. Prostaglandin also improves sperm quantity in the canine ejaculate would benefit all assisted reproductive techniques used in all species (Milan, 2002). In fish, exogenous prostaglandins also show stimulatory effect on the induction of ovulation. F prostaglandins also function as a hormone that stimulates female sexual behavior (Sorensen et al., 1988; Davidson et al., 2008). It is now cleared that this compound is also functioning as potent olfactory stimulants with pheromonal activity in human (Karl et al., 2005) and for many species of fish (Sorensen and Goetz, 1993). At the time of ovulation female goldfish produce large quantities of prostaglandin (PGF2) which acts as hormone to trigger spawning (oviposition) behaviors (Stacey and Peter, 1979) which being metabolized and released where males recognized it as a releaser pheromone (Sorensen and Goetz, 1993; Sorensen et al., 1995; Stacey and Sorensen, 2002). Recently, ovulated goldfish release great quantities of $\mathrm{PGF}_{2} \alpha$ and a metabolites 15 -Keto prostaglandin in urinary pulses whose frequency changes during spawning (Appelt and Sorensen, 1999). According to Sorensen et al., 1995a, 2000 prostaglandin is a potent sex attractant. Fish commonly use reproductive hormone (steroids and prostaglandin) both as endogenous signals between reproductive tract and brain and as exogenous signals (hormonal pheromones) that synchronize gamete maturation and/or spawning interaction between and among conspecifics (Stacey, 2003). The metabolites prostaglandin F2 $\alpha$ (PGF2 $\alpha$ ) like 15 $\alpha$-Keto-13, 14-dihydro$15 \alpha$-Keto to function as releaser pheromone in the goldfish, fathead minnow and cobitid loach (Stacey and Sorensen, 2002; Kitamura et al., 1994). Critical hormonal functions in the female, $17 \alpha, 20 \alpha-\mathrm{p}$ and prostaglanderis (PGS) are released into the water where they function as potent chemical cues eliciting significant changes in the reproductive physiology and behavior of male. $\mathrm{F}$ prostaglandins are potent chemical stimulants in cypriniformes and suggest that $\mathrm{F}$ prostaglandin may be commonly used as sex pheromone in cypriniformes (Kitamura et al., 1994). Studies on the efficacy of prostaglandin on reproduction in relation to pituitary gonadal axis in the fish, Cyprinus carpio (L.) is meager and hence the present work is an attempt in this direction to assess its potency as an inducer to achieve early maturity leading to successful breeding.

\section{MATERIALS AND METHODS}

Experimental animals: Maturing male and female of $C$. carpio were collected in the month of December (prior to their spawning season) from government fish farm located at Shivani bandh, Gothangaon and some from International Meritech pvt. Ltd.at Satak. Fish were sexed by the genital papilla. Males and females were housed in a separate cylindrical fibre glass tanks having capacity of $1000 \mathrm{~L}$ of water provided with proper aeration and floating aquatic weeds echhornia ( for the purpose of adhesion of eggs) and acclimatized to the laboratory ISSN : 0974-9411 (Print), 2231-5209 (Online) All Rights Reserved ๑ Applied and Natural Science Foundation www.ansfoundation.org 
conditions. Fish were maintained on a diet of soybean, rice bran and oilcake in the form of pellets. The quantity of the diet was readjusted weekly as per the weight and condition of the fish.

Experimental design: Control and experimental groups were formed by keeping males and females separately where they were maintained for five weeks (up to fifth dose). Males and females of control group were injected with $1.5 \mathrm{ml}$ of distilled water and experimental group were injected intramuscularly with $1.5 \mathrm{ml}$ of prostaglandin up to sixth dose. For sixth dose, the spermiating male with rough dorsal surface of pectoral fin and ovulatory female with smooth dorsal surface of pectoral fin were selected and maintained together in the ratio of 2:1 to observe the sexual behavior ( at interval of $15 \mathrm{~min}$.) and breeding of fully mature fishes. At the end of fifth week of treatment, single male and single female of control and treated groups were sacrificed to study the histomorphological changes in endocrine glands like pituitary and gonads by using histological process in which they were fixed in Bowin's solution for $24 \mathrm{~h}$. Tissues were dehydrated, cleared and embedded in paraffin wax, sectioned at 6-8 $\mu$ spreaded on slides and stained with different staining techniques. Sections were analyzed micro photographically.

\section{RESULTS}

Control group: The pituitary gland of control group consisted of cyanophil, chromophobes and acidophils. In the proximal portion of pars distalis, there were cyanophils as seen from their affinity towards AF and PAS-stain. These cyanophil cells were angular or spindle in shape $(7.55 \pm 0.37 \mu)$. Orangeophils measured about $6.82 \pm 0.38 \mu$ (Table 1) and histologically less AF+ve secretion was observed in the olfactory bulb and tract.

The ovary was in the maturing phase. Histologically oocyte showed small clear yolk vesicles and nucleus with undulated nuclear membrane. Testis were opaque and in the maturing phase. In a section, a large number of primary, secondary spermatocytes and spermatids were visible. After injecting distilled water to the control group, no sign of courtship was observed even after the second dose.

Experimental group: In the pituitary gland of experimental group, the number of AF and PAS - positive cells was increased through the PPD (Fig. 1). Size of the cells showed significant rise $(8.60 \pm 0.36 \mu)$ (Table 1) as compared to that of the control fish. Some cyanophils were turgid and some were in the secretary phase. Some gonadotrops were vacuaolated (Fig. 1). Increased granular secretion was observed in olfactory bulb and tract as compared to that of control.

At the end of $5^{\text {th }}$ dose, the ovaries were in prespawning phase. The fish was gravid with rounded abdomen, eggs oozed out on pressing abdomen and histologically, a large number of oocytes with fused yolk vesicles, yolk globules and migrating nucleus with ripe egs were seen in a section and became ready to spawn(Fig.2). There was considerable increase in the weight and volume of testis which becomes turgid. Histologically, the seminiferous tubules were increased in size, full of sperms and with some releasing sperms (Fig. 3). The spermatogonia were reduced in number while all other stages of spermatogenesis were seen in the tubule (Fig. 3) and milt oozed out on pressing the abdomen of the fish.

After the fifth week, male and female were kept together (2:1) in a breeding tank. After 3 hours of second injection, they started swimming actively, became excited and restless. Female was chased by the males pushing her with snout and after 4 hours of second injection, spawning occurred (Fig .4)

\section{DISCUSSION}

Prostaglandin F2 $\alpha$ act as pheromone which induce sexual behavior in vertebrates. The present results reveal that prostaglandin $\mathrm{F}_{2} \alpha$ plays an important role in maturation and ovulation of fish C. carpio. Male and female both exhibit an increased frequency of courtship behavior following prostaglandin $\mathrm{F}_{2} \alpha$ treatment which is also supported by the views of Kobayashi et al. (2002) and Stacey and Sorensen (2002). They also reported that prostaglandin $\mathrm{F}_{2} \alpha$ appears to induce the release of a female specific chemical in fathead minnows that triggers courting behavior in conspecific male. Present study investigated the possibility of prostaglandin $\mathrm{F}_{2} \alpha$ may have pheromonal role in $C$. carpio as it stimulates both male and female to breed easily by exhibiting vigorous courtship. Moore and Waring (1996) observed the pheromonal role of $\mathrm{PGF}_{2} \alpha$ in Atlantic Salman by measuring the olfactory sensitivity acting as a potent odourant in mature salmon. Sorensen and Goetz (1993) stated that $\mathrm{PGF}_{2} \alpha$ play a paracrine role in the ovary of teleost fish stimulating and modulating follicular rupture, circulating levels of $\mathrm{PGF}_{2} \alpha$ rise at the time of ovulation and travel to the brain where they elicit female sexual behavior. $\mathrm{PGF}_{2} \alpha$ act as endogenous signals (hormones) to synchronise spawning behaviour with gamete maturation within each individual and as exogenous signals (pheromone) to synchronise sexual interactions between conspecifics. In the presence study, $\mathrm{PGF}_{2} \alpha$ also stimulates oocyte maturation in Cyprinus carpio. At the time of ovulation female gold fish oviducts synchronise

Table 1. Cell diameter of cynophils and orangeophil.

\begin{tabular}{lcc}
\hline Cell & Control & Prostaglandin \\
\hline Cyanophils & $7.55 \pm 0.37$ & $8.60 \pm 0.36$ \\
Orangeophils & $6.82 \pm 0.38$ & $7.45 \pm 0.30$ \\
\hline
\end{tabular}

All measurements are in $\mu, p<0.01, p<0.001, p<0.005$, $\mathrm{p}<0.025, \pm 0$ Standard 


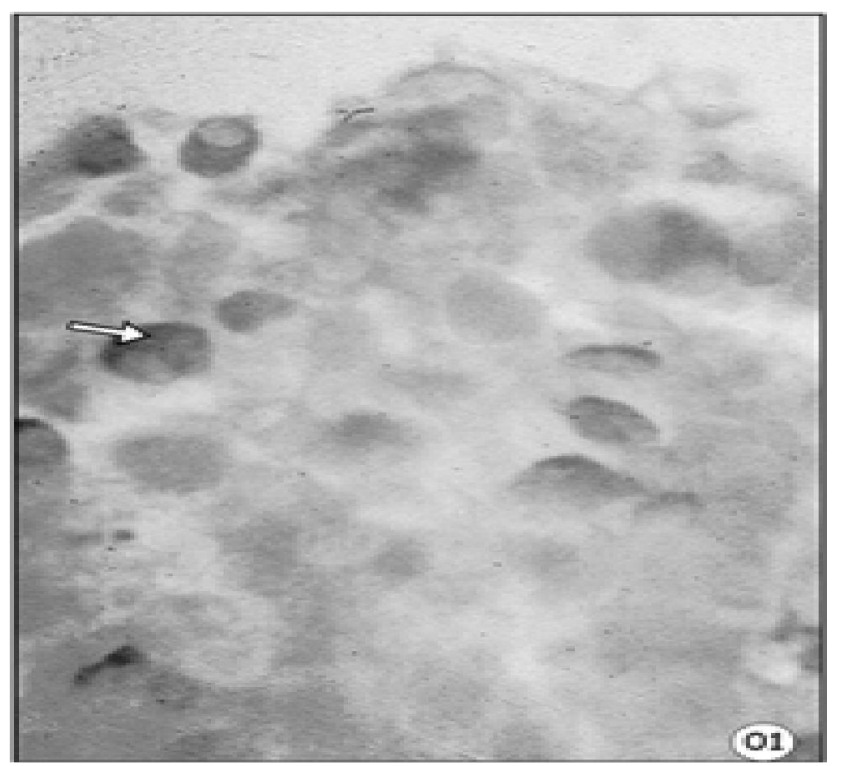

Fig. 1. Pituitary gland showing turgid cyanophils $(\longrightarrow) \times 100$.

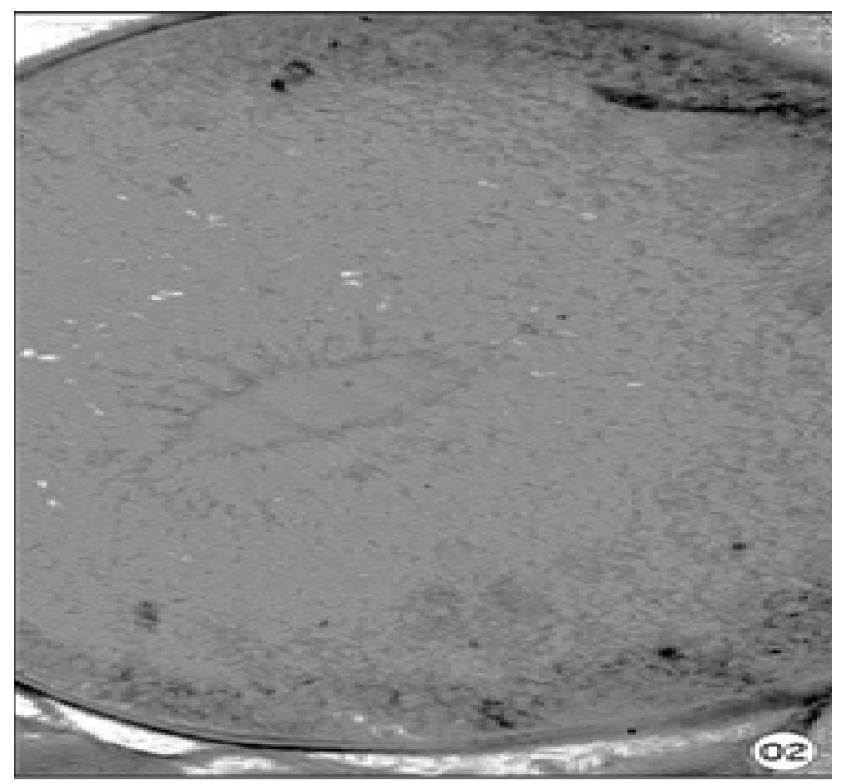

Fig. 2. Mature oocyte with disappearing nucleus. X45.

and secrete $\mathrm{PGF}_{2} \alpha$ that induces reproductive behaviour (Stacey and Peter, 1979; Sorensen et al., 1988). PGF $_{2} \alpha$ and its metabolites mainly 15 keto - $\mathrm{PGF}_{2} \alpha$ are also released into water as post ovulatory pheromone that induce male spawning behavior and further increase male GTH - II and sperm production to stimulate the GTH - II (Sorensen et al., 1988; Sorensen et al., 1989; Sorensen and Goetz 1993and Laberge and Hara, 2003). Present studies also indicate that $\mathrm{F}$ prostaglandin is metabolised and released to the water where it functions as a sex pheromone. Therefore, $\mathrm{PGF}_{2}$ á also plays a dual role as a para hormone and hormone, synchronising male and female sexual behavior in Cyprinus carpio. Davidson et al., 2008 have found that exposure to water borne $\mathrm{PGF}_{2}$ increased neurogenesis and $\mathrm{GnRH}$ concentration in male

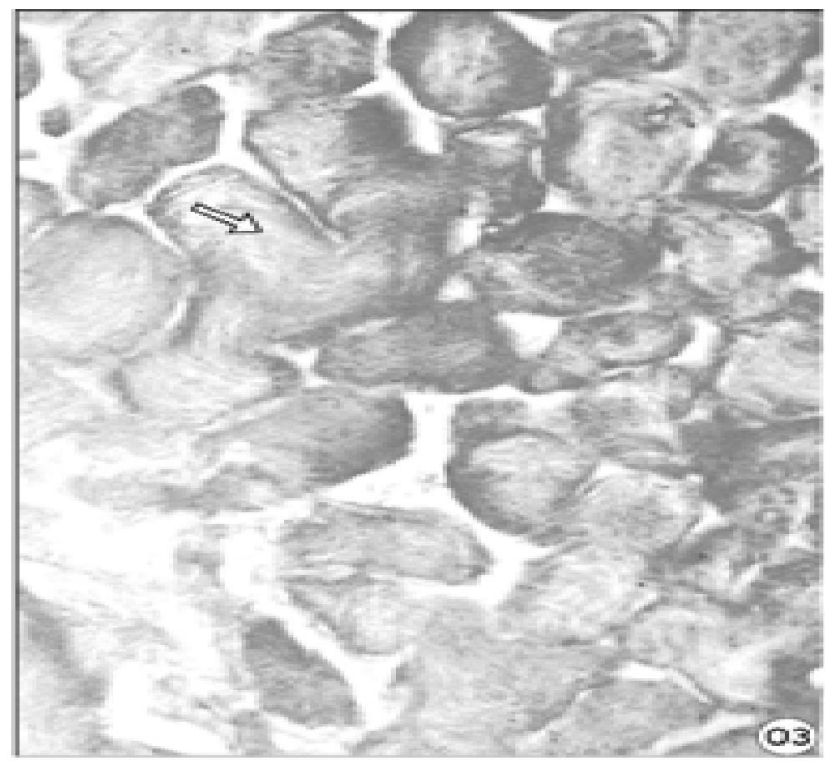

Fig. 3. Testis showing many seminiferous tubules filled with sperms $(\longrightarrow)$ X 10 .

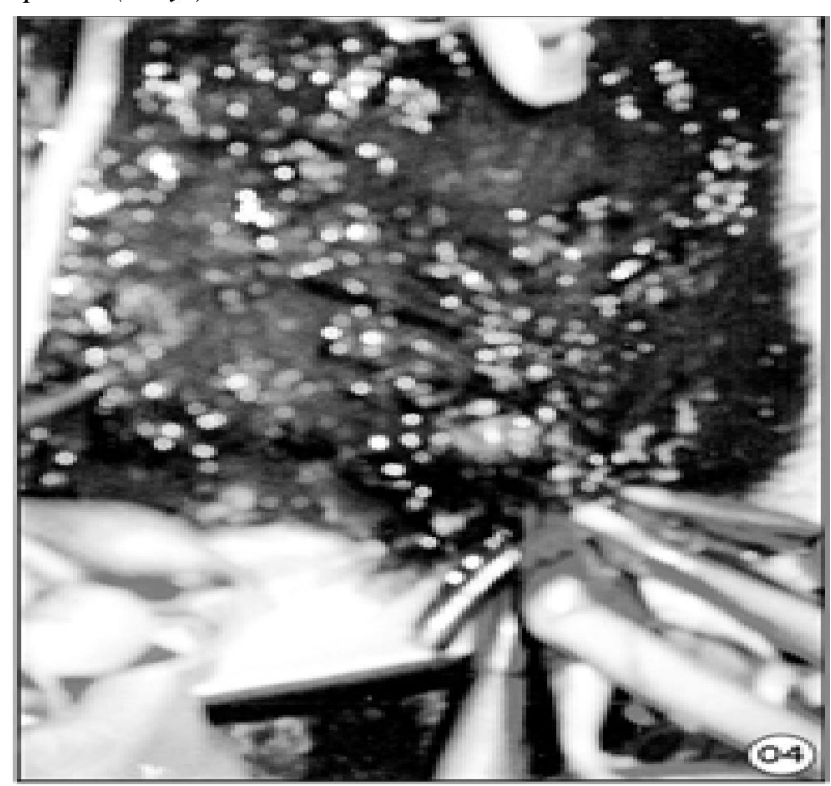

Fig. 4. Eggs attached to the roots of aquatic plantafter spawning.

goldfish brain and modulate brain plasticity associated with behavioral changes during spawning season via the neuroendocrine $(\mathrm{GnRH})$ and motor components of the pheromone-reproductive system. This finding confirms the above view in C. carpio in relation with increased number of gonadotrops, olfactory secretion. Kitamura et al. (1994) suggested that F prostaglandin may be commonly used as sex pheromone in Cypriniformes. Milan Hess (2002) demonstrated that sexual preparation involves release of $\mathrm{PGF}_{2}$ á which stimulates contraction of the male excurrent duct system of dog increasing sperm number in the ejaculate. In the fish, C. carpio sexual preparation like intensive courtship with maximum number of sperms in the testis has been observed with the $\mathrm{PGF}_{2} \alpha$ treatment as well as the number 
of the interstitial cells has also been increased in the testis of the fish C. carpio. Interestingly, like mammals there are indications that olfactory function in the $C$. carpio may be modulated by circulating prostaglandin, acting as sex pheromones in C. carpio.

\section{Conclusion}

Prostaglandin had stimulatory effect on the gonadal secretion, in male and female via olfacto-hypothalamohypophysial pathway as neuroethological mechanism closely associated with olfactory function. As the maturing fish became mature due to the treatment, a successful breeding had been observed by the end of the experiment in the laboratory condition. Thus, the results obtained from the present study, it can be concluded that prostaglandin acts as an inducer and definitely activates the pituitary gonadal axis leading in to breeding.

\section{REFERENCES}

Appelt, C. W. and Sorensen, P.W. (1999). Fresh water fish release urinary pheromone in a pulsatile manner. Advances in chemical signals in Vertebrates. Kluwer Academic / Plenum publisher. New York.

Davidson, Yu-Wen-Chung.,ChristopherBenjamin Rees., Mara.Beth Bryan and Weiming, Li.(2008). Neurogenic and neuroendocrine effects of goldfish pheromones.The J ournal of Neuroscience, 28(53): 14492-14499.

Karl Grammer., Bernhard, Fink. and Nick, Neave. (2005). Human pheromones and sexul attraction. E uropean J ournal of Obstetrics and Gynecology and Reproductive Biology, 118: 135-142.

Kitamura, S., Ogata, H. and Takashima, F. (1994). Olfactory responses of several species of teleost to F- Prostaglandin. Comp. Biochem. Physiol., 107 A, (3): 463 - 467.

Kobayashi, M., Sorensen, P. W. and Stacey, N. E. (2002). Hormonal and pheromonal control of spawning behavior in the goldfish. Fish Physiol. Biochem., 26: $71-84$.

Laberge, F. and Hara, T. J. (2003). Behavioral an electrophysiological responses to $\mathrm{F}$ - prostaglandin, putative spawning pheromone in three salmonid fishes. Journal of Fish Biology, 62: 1206 - 221
Milan, B. Hess. (2002). The effect of prostaglandin $\mathrm{F}_{2} a$, oxytocin and gonadotropin releasing hormone in ejaculate characteristic in the Dog (Thesis).Virginia Polytechnic Institute and State University, Blacksburg, Virginia.

Moore, A. and Colin, P. Waring (1996). Electrophysiological and endocrinological evidence that $\mathrm{F}$ series prostaglandins function as priming pheromones in mature male Atlantic salmon (Salmo salar) parr. The J ournal of Experimental Biology, 199: 2307 - 2316.

Sorensen, P. W. and Goetz, F.W. (1993). Pheromonal and reproductive functions of $\mathrm{F}$-prostaglandin and their metabolites in teleost fish. J. Lipid Med., $6: 385-393$.

Sorensen, P. W. and Stacey, N. E. and Chamberlain, K. J. (1989). Differing behavioral and endocrinological effects of two female sex pheromones on male goldfish. H orn. B ehav. $23(3): 217-32$

Sorensen, P. W., Hara, T. J., Stacey, N. E. and Goetz, F. W. (1988). F- Prostaglandin functions as potent olfactory stimulants that comprise the post-ovulatory female sex pheromone in goldfish. Biol. Reprod., 39: 1039 -1050.

Sorensen, P. W., Scott, A. P. and Kihslinger, R. L. (2000). Proceedings of the sixth international symposium on the reproductive physiology of fish. Bergien, Institute of Marine Research and University of Bergen. pp. 125-128.

Sorensen, P. W., Scott, A. P., Stacey, N. E. and Bowdin, L. (1995). Sulphated $17,20 \alpha$ - dihydroxy - 4 pregnen - 3- one function as a potent and specific olfactory stimulant with pheromonal actions in the goldfish. Gen. Comp. Endocrinal., 100: 128-142.

Sorensen, P. W., Scott, A. P., Stacey, N. E., Bowdin, L. (1995a). Sulphated 17, 20 $\alpha$ - dihydroxy - 4 pregnen - 3 - one function as a potent and specific olfactory stimulant with pheromonal actions in the goldfish.General and Comparative Endocrinology, 100 : 128-142.

Stacey, N. E. (2003). Hormones, pheromones and reproductive behavior. J. Fish. P hysiol./ Biochem, 28 (1-4) : 229 - 235.

Stacey, N. E. and Peter, R. E. (1979). Central action of prostaglandin in spawning behavior of female goldfish. Physiol Behav., 22 : 1191-1196.

Stacey, N. E. and Sorensen, P. W. (2002). Fish hormonal Pheromones. In : (P falfd, Arnold, D., Ategen. A, Farbachs Rubin R. eds), Hormones, brain and behavior. New York : Academy.Vol. 2 (pp. 375-435). 